\title{
Early relief of upper gastrointestinal dyspeptic symptoms: A survey of empirical therapy with pantoprazole in Canadian clinical practice
}

\author{
David Armstrong MA FRCPUK FRCPC ${ }^{1}$, Farouk Kazim MSc MA ${ }^{2}$, Marcel Gervais BSc ${ }^{3}$, \\ Myron Pyzyk BSc MS 4
}

D Armstrong, F Kazim, M Gervais, M Pyzyk. Early relief of upper gastrointestinal dyspeptic symptoms: A survey of empirical therapy with pantoprazole in Canadian clinical practice. Can J Gastroenterol 2002;16(7):439-450.

BACKGROUND: Upper gastrointestinal symptoms attributable to gastroesophageal reflux disease or peptic ulcer are common, but the outcome of proton pump inhibitor therapy in clinical practice is not well documented.

AIM: To assess the range of upper gastrointestinal acid-related symptoms in clinical practice and the rapidity of their response to pantoprazole ( $40 \mathrm{mg}$ daily), after seven days of therapy.

METHODS: A total of 726 Canadian physicians (65.3\% family physicians) recorded a working diagnosis and alarm features in eligible patients, who then recorded the severity of eight upper gastrointestinal symptoms in a daily symptom diary during the first week of therapy.

RESULTS: Complete data were obtained from 2273 (37.3\% male) of 3261 patients; physicians diagnosed reflux esophagitis alone $(66.9 \%)$, peptic ulcer $(9.7 \%)$, other upper gastrointestinal disorders $(12.3 \%)$ and reflux esophagitis with another diagnosis (11.1\%). Alarm features were common (29.6\%), but a history of gastrointestinal blood loss was rare (less than $1 \%)$. Mean daytime heartburn scores decreased from 2.59 to 1.40 , and epigastric pain scores decreased from 2.54 to 1.56 over the first week $(\mathrm{P}<0.00001)$; the proportions of patients who became symptomfree were $68.1 \%$ and $55.4 \%$, respectively. Decreased mean symptom scores were also observed for acid regurgitation (2.21 to 1.35 ), bloating (2.47 to 1.57 ), nausea (2.03 to 1.36 ), slow digestion (2.51 to 1.56$)$ and burping (2.56 to 1.69$)$. The percentage of patients with severe or very severe symptoms decreased from $53.5 \%$ to $13.8 \%$ at day 7 . The physician's initial diagnosis was not predictive of outcome.

CONCLUSIONS: In a predominantly primary care population with upper gastrointestinal acid-related symptoms, proton pump inhibitor therapy produces prompt symptomatic relief in most patients. Potential alarm symptoms are common, and further research is required to determine the absolute risk of alarm symptoms and their implications for empirical therapy.

Key Words: Acid-related symptoms; Dyspepsia; Gastroesophageal reflux disease; Pantoprazole; Proton pump inhibitor; Upper gastrointestinal dyspeptic symptoms

Résumé à la page suivante

${ }^{1}$ Division of Gastroenterology, McMaster University, Hamilton, Ontario; ${ }^{2}$ Clinical R $\&$ D Network, Oakville, Ontario; ${ }^{3}$ Clinical Monitoring Group, Moncton, New Brunswick; ${ }^{4}$ Solvay Pharma Inc, Scarborough, Ontario

Correspondence: Dr D Armstrong, Division of Gastroenterology, HSC-4W8, McMaster University Medical Centre, 1200 Main Street West, Hamilton, Ontario L8N 325. Telephone 905-521-2100 ext 76404, fax 905-521-4958, e-mail armstro@mcmaster.ca

Received for publication August 7, 2001. Accepted April 22, 2002 


\section{Le soulagement précoce des symptômes dyspeptiques gastro-intestinaux : Enquête sur un traitement empirique au pantoprazole en pratique clinique au Canada}

\author{
HISTORIQUE : Les symptômes gastro-intestinaux supérieurs \\ attribuables au reflux gastro-œsophagien ou à l'ulcère peptique sont \\ courants, mais les résultats d'un traitement par inhibiteur de la pompe à \\ protons en pratique clinique n'est pas bien documenté. \\ OBJECTIF : Évaluer la gamme de symptômes gastro-intestinaux \\ supérieurs reliés à l'acide en pratique clinique et la rapidité de la réaction \\ au pantoprazole (40 mg par jour), après sept jours de traitement. \\ MÉTHODOLOGIE : Au total, 726 médecins canadiens (65,3\% de \\ médecins de famille) ont posé un diagnostic provisoire et observé des \\ caractéristiques d'alarme chez les patients admissibles, qui ont ensuite \\ inscrit quotidiennement la gravité de huit symptômes gastro-intestinaux \\ dans un journal au cours de la première semaine de traitement. \\ RÉSULTATS : Des données complètes ont été obtenues à l'égard de \\ 2273 (37,3\% d'hommes) patients sur 3 261. Les médecins ont diagnos- \\ tiqué une œsophagite peptique seule $(66,9 \%)$, un ulcère peptique
}

$(9,7 \%)$, d'autres troubles gastro-intestinaux supérieurs $(12,3 \%)$ et une œsophagite peptique accompagnée d'un autre diagnostic (11,1\%). Les caractéristiques d'alarme étaient courantes (29,6\%), mais les antécédents de perte sanguine gastro-intestinale étaient rares (moins de $1 \%$ ). L'indice moyen de brûlures d'estomac a fléchi de 2,59 à 1,40, et l'indice de douleurs épigastriques est passé de 2,54 à 1,56 au cours de la première semaine $(\mathrm{P}<0,00001)$. La proportion de patients qui sont devenus asymptomatiques était de $68,1 \%$ et de $55,4 \%$, respectivement. Une diminution de l'indice moyen des symptômes s'observait également pour ce qui est de la régurgitation acide $(2,21$ à 1,35$)$, des gonflements $(2,47$ à 1,57$)$, des nausées $(2,03$ à 1,36$)$, de la lenteur de la digestion $(2,51$ à 1,56$)$ et des rots $(2,56$ à 1,69$)$. Le pourcentage de patients souffrant de symptômes graves ou très graves avait chuté de 53,5 \% à 13,8 \% le septième jour. Le diagnostic initial du médecin n'était pas prédicteur de l'issue.

CONCLUSIONS : Dans une population souffrant de symptômes gastrointestinaux supérieurs reliés à l'acide observée dans un milieu à prédominance de soins de premier recours, le traitement par inhibiteur de la pompe à protons produit un soulagement symptomatique rapide chez la plupart des patients. Les caractéristiques d'alarme potentielles sont courantes, et des recherches plus approfondies s'imposent pour établir le risque absolu de ces caractéristiques et leurs répercussions sur un traitement empirique.

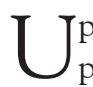
pper gastrointestinal symptoms are common, with prevalence rates of $25 \%$ to $50 \%$. In Canada, the prevalence of upper gastrointestinal symptoms was reported to be $29 \%$ in a general population survey (1), and it has been estimated that the management of upper gastrointestinal symptoms accounts for $7 \%$ of primary care office visits in Canada (2). Upper gastrointestinal dyspeptic symptoms may be attributable to an identifiable condition, such as peptic ulcer, erosive esophagitis or even gastric cancer, although, in up to $50 \%$ of individuals, no cause can be found $(3,4)$. The etiology of upper gastrointestinal symptoms in these patients is unclear, but many have acidrelated symptoms, in the absence of lesions. For example, up to one-half of patients with gastroesophageal reflux disease (GERD) do not have erosions or 'mucosal breaks' (5), and it is now recognized that they have endoscopy-negative reflux disease (ENRD) (6).

A diagnosis of ulcer disease or erosive esophagitis requires that the patient undergo investigation to identify the underlying organic lesion, and it is not possible, therefore, to diagnose ENRD or nonulcer dyspepsia (NUD) without a prior endoscopy. In principle, it would be preferable if treatment for a patient with upper gastrointestinal symptoms were based on a definitive diagnosis, but, in practice, most of these patients are managed by primary care physicians who have only limited access to endoscopy. It has been proposed that the constellation of upper gastrointestinal dyspeptic symptoms can be used to define subgroups - 'reflux-like', 'ulcer-like' and 'dysmotility-like' - that would facilitate management $(7,8)$. Although the patient's symptoms rarely allow the physician to make a definitive diagnosis of ulcer disease or nonulcer dyspepsia $(3,9)$, symptoms such as heartburn or regurgitation are useful in diag- nosing GERD (10). It is less clear whether the patient's symptoms are predictive of a response to acid suppression therapy. If, for example, acid suppression with a proton pump inhibitor (PPI) were effective only in patients with reflux symptoms, physicians could restrict empirical therapy to these patients and proceed more rapidly with investigations in the remaining patients.

Patients who present for the first time with upper gastrointestinal symptoms are considered to have 'uninvestigated dyspepsia', and many of these patients can now be treated appropriately without the need for endoscopy, provided that they do not manifest any alarm features (3). Furthermore, waiting lists for a gastroenterology consultation and endoscopy are often so long that initial empirical therapy is necessary, even for patients who will eventually undergo investigation. Under these circumstances, it is important to know the extent to which empirical therapy is appropriate and effective in the broad group of patients with upper gastrointestinal dyspeptic symptoms. Many other patients with upper gastrointestinal symptoms already have a diagnosis of GERD or peptic ulcer disease based on prior investigations such as endoscopy or upper gastrointestinal radiography. For these patients, continued therapy with acid suppression agents is appropriate provided that the patient has developed no alarm features or significant changes in symptoms since diagnosis.

A multicentre, Canadian survey was conducted in collaboration with family physicians, surgeons, internists and gastroenterologists. The aims of the survey were to evaluate the range of upper gastrointestinal dyspeptic symptoms in Canadian patients considered to have upper gastrointestinal tract disease and to determine their responses, at seven days and 28 days, to treatment with a PPI, pantoprazole. 
Data on symptom response after 28 days of therapy and the relationship between symptoms and changes in healthrelated quality of life will be reported separately.

\section{PATIENTS AND METHODS}

The survey was designed to recruit patients, predominantly in a primary care practice setting, who had symptoms referable to the upper gastrointestinal tract, including symptoms consistent with diagnoses of reflux disease or peptic ulcer disease. The objective was to collect data from 2500 patients under the care of 1000 physicians from across Canada, as a representative sample of patients with upper gastrointestinal dyspeptic symptoms in daily practice. Physicians who had been identified as treating a relatively high volume of patients with gastrointestinal tract conditions were contacted directly by mail and then recruited by telephone follow-up to determine whether they would be prepared to enrol patients in the survey.

Participating physicians were asked to enrol five patients with upper gastrointestinal dyspeptic symptoms that would be expected to respond to acid suppression therapy with a PPI (pantoprazole, Pantoloc, Byk Canada Inc, and Solvay Pharma Inc, Canada). Physicians were advised that a small charitable donation $(\$ 10.00)$ would be made, in their name, for each patient whom they enrolled.

All investigators completed a patient enrolment form, on which they indicated the presumptive, working diagnosis (reflux esophagitis, gastric ulcer, duodenal ulcer or other), the presence of possible alarm features (weight loss, dysphagia, odynophagia, vomiting, melena, asthma, hematemesis) and the presence of other concomitant illnesses requiring therapy (although the precise nature of any concomitant illness was not recorded). The investigators were not asked to specify how the working diagnoses of reflux esophagitis or peptic ulcer disease had been made, to differentiate between erosive esophagitis or endoscopy-negative reflux disease, or to record the presence of any other potential alarm features. The enrolment form was mailed to the Clinical Monitoring Group (Moncton, New Brunswick) for verification and data entry. The date of enrolment was recorded and used to predict the date of completion of therapy and the likely date of receipt of the completed patient questionnaire. No follow-up data were requested from the investigator after the enrolment form had been mailed in; specifically, there was no record of whether patients had been referred for further investigation.

Based on a review of the design of the survey with the chair of the local Institutional Review Board (McMaster University, Hamilton, Ontario) it was determined that this was not a formal study requiring a patient consent form, but rather that it was a voluntary survey and that the patients' consent was implicit in their decision to complete the survey and return it to the data entry centre.

After initiation into the study, the physicians gave patients a bottle containing a one-month supply of pantoprazole $40 \mathrm{mg}$ tablets, a patient information brochure and a questionnaire, which included a daily symptom diary to be completed during the first seven days of therapy with pantoprazole. Before taking the first dose of pantoprazole, patients were instructed to complete the pretherapy questionnaire, as well as the first column of the daily symptom diary (day $0=$ baseline). They were then instructed to take one tablet daily, in the morning, for 28 days.

The pretherapy questionnaire collected data concerning the patient's quality of life and history of upper gastrointestinal problems. The patients were then asked to record in a daily diary the severity of eight specific, dyspepsia symptoms $(4,7,8)$, referable to the upper gastrointestinal tract, for the first seven days of therapy (day 1 to day 7 inclusive), at approximately the same time every day. They were instructed to complete the diary even if they had missed taking their medication on that particular day. The eight symptoms, for which severity was recorded in the daily symptom diary, were:

A. Did you experience heartburn during the day? ('Daytime heartburn')

B. Did you experience heartburn during the night? ('Nocturnal heartburn')

C. Did you experience an acid or sour taste in the back of your throat or mouth? ('Acid regurgitation')

D. Did you experience pain or aching in the stomach region? ('Epigastric pain')

E. Did you experience bloating (a feeling of stomach distension)? ('Bloating')

F. Did you experience nausea or a feeling of sickness? ('Nausea')

G. Did you experience a feeling of fullness or slow digestion lasting $2 \mathrm{~h}$ after a normal-sized meal? ('Slow digestion')

H. Did you have burping or belching? ('Burping')

For the purposes of the daily diary, heartburn was defined as "a burning feeling rising from the stomach or lower part of the chest" (10). Based on the symptoms recorded in the daily diary, patients were identified as having 'reflux-like' symptoms (symptoms A, B and C), 'ulcer-like' symptoms (symptom D) or 'dysmotility-like' symptoms (symptoms E, F, $G$ and $H)(4,7,8)$. For each of the eight symptoms detailed above, the patients were asked to rate their severity on a five-point scale:

1. No - None

2. Mild - Can be ignored when I don't think about it

3. Moderate - Cannot be ignored, but does not influence daily activities 
TABLE 1

Geographic distribution of patients, physicians and physician specialties (family physician [FP], general internal medicine specialist [internist] and subspecialty gastroenterologist [Gastro]) who participated in a study on the relief of upper gastrointestinal dyspeptic symptoms with the use of a proton pump inhibitor

\begin{tabular}{|c|c|c|c|c|c|}
\hline Province & FP & Surgeon & Internist & Gastro & Total \\
\hline Maritimes & 64 & 0 & 2 & 6 & 72 \\
\hline Quebec & 113 & 3 & 1 & 9 & 126 \\
\hline Ontario & 238 & 13 & 12 & 34 & 297 \\
\hline Manitoba & 62 & 9 & 4 & 3 & 78 \\
\hline Saskatchewan & 23 & 5 & 0 & 0 & 28 \\
\hline Alberta & 50 & 3 & 0 & 3 & 56 \\
\hline British Columbia & 51 & 6 & 3 & 9 & 69 \\
\hline Total number of physicians (\%) & $601(82.8)$ & $39(5.4)$ & $22(3.0)$ & $64(8.8)$ & $726(100)$ \\
\hline $\begin{array}{l}\text { Total number of patients } \\
\text { enrolled (\%) }\end{array}$ & $2128(65.3)$ & $350(10.7)$ & $445(13.6)$ & $338(10.4)$ & $3261(100)$ \\
\hline
\end{tabular}

\section{TABLE 2}

Reasons for the failure of 988 patients to complete questionnaires on the relief of upper gastrointestinal dyspeptic symptoms with the use of a proton pump inhibitor*

\begin{tabular}{lc}
\hline Reason for failure to complete & $\mathbf{n}(\%)$ \\
\hline $\begin{array}{l}\text { Unable to contact patient or presence of } \\
\text { language barrier }\end{array}$ & $389(39.4)$ \\
Patient refused to complete questionnaire & $405(41.0)$ \\
No reason given (missing) & $78(7.9)$ \\
Patient did not take any of the medication & $52(5.3)$ \\
Patient discontinued the study medication & $38(3.8)$ \\
Patient lost to follow-up & $14(1.4)$ \\
Other & $12(1.2)$ \\
Total & $988(100)$ \\
\hline
\end{tabular}

${ }^{*}$ These patients were excluded from the final analysis

4. Severe - Influences my concentration on daily activities

5. Very severe - Markedly influences my daily activities and /or requires rest.

When patients had finished the prescribed therapy after 28 days, they were instructed to answer all remaining questions in the questionnaire booklet and return it to the Clinical Monitoring Group.

Data management and analysis

Upon receipt by the Clinical Monitoring Group, the patient questionnaires were checked to verify accuracy and to identify missing or implausible data. Data were then entered into a customized, relational database. In the event that information was incomplete or illegible, or that the questionnaire had not been received by the date projected from the initiation form, the Clinical Monitoring Group contacted the patient by telephone to complete or clarify the necessary information. Patients were then sent a small honorarium $(\$ 10.00)$, in recognition of the time taken to complete the questionnaire. Once data entry had been completed for all questionnaires (FileMaker Pro v4.5, Claris Corporation, USA), the database was locked and the data were exported for statistical analysis. All data were stored in a secure database and, to ensure patient confidentiality, no individual patient was identifiable following data verification.

Baseline demographic features, recorded by the physician in the initiation form, were compared for patients who completed the questionnaire and for patients who were initiated but failed to return the questionnaire. Symptom severity scores were analyzed to calculate changes with respect to time, the physicians' initial diagnosis, the presence or absence of alarm features, the presence or absence of a concomitant illness, and the presence and frequency of reflux symptoms (determined by the question "Did you experience a rising, spreading burning sensation behind your breastbone (heartburn)?") or ulcer symptoms (determined by the question "Have you had pain or discomfort in the upper abdomen [above the belly button] such as burning, bloating or fullness?"). The frequencies of the reflux and ulcer symptoms were rated on a five-point scale (1 'none of the time', 2 - 'a little of the time', 3 - 'some of the time', 4 - 'most of the time' and 5 - 'all of the time'). Statistical analysis was performed, when appropriate, using the paired $t$ test, to determine the change in symptom severity that occurred in response to treatment and the $\chi^{2}$ test to test for differences in proportions between symptom groups. 
TABLE 3

Prevalence of alarm symptoms or features of serious disease in evaluable patients compared with those excluded from the analysis because of failure to complete their questionnaires

\begin{tabular}{|c|c|c|c|c|c|c|}
\hline & \multicolumn{3}{|c|}{ Patients excluded from analysis $(n=988)$} & \multicolumn{3}{|c|}{ Evaluable patients $(n=2273)$} \\
\hline & Yes (\%) & No (\%) & Yes (\%) & No (\%) & N/A (\%) & $\mathbf{P}$ \\
\hline Concomitant illness & $396(40.1)$ & $592(59.9)$ & $1043(45.9)$ & $1226(53.9)$ & $4(0.18)$ & 0.00213 \\
\hline Dysphagia & $177(17.9)$ & $811(82.1)$ & $449(19.8)$ & $1820(80.1)$ & $4(0.18)$ & 0.231 \\
\hline Odynophagia & $99(10.0)$ & $889(90.0)$ & $278(12.2)$ & $1991(87.6)$ & $4(0.18)$ & 0.0766 \\
\hline Vomiting & $117(11.8)$ & $871(88.2)$ & $213(9.37)$ & $2058(90.5)$ & $2(0.09)$ & 0.0376 \\
\hline Asthma & $62(6.28)$ & $926(93.7)$ & $142(6.25)$ & $2129(93.7)$ & $2(0.09)$ & 0.0821 \\
\hline Weight loss & $54(5.47)$ & $934(94.5)$ & $133(5.85)$ & $2137(94.0)$ & $3(0.13)$ & 0.0717 \\
\hline Melena & $28(2.83)$ & 960 (97.2) & $36(1.58)$ & 2234 (98.3) & $3(0.13)$ & 0.0268 \\
\hline Hematemesis & $16(1.62)$ & $972(98.4)$ & $16(0.70)$ & 2254 (99.2) & $3(0.13)$ & 0.0251 \\
\hline
\end{tabular}

$P$ values for difference in proportions, $\chi^{2}$ test. N/A Data not available

TABLE 4

Demographics of the $\mathbf{2 2 7 3}$ evaluable patients with respect to physicians' initial diagnosis at enrolment in a study of the relief of upper gastrointestinal dyspeptic symptoms with the use of a proton pump inhibitor

\begin{tabular}{|c|c|c|c|c|c|}
\hline & $\begin{array}{l}\text { Reflux esophagitis } \\
\text { alone (\%) }\end{array}$ & $\begin{array}{l}\text { Peptic ulcer plus } \\
\text { other diagnosis (\%) }\end{array}$ & $\begin{array}{c}\text { Other } \\
\text { diagnosis (\%) }\end{array}$ & $\begin{array}{l}\text { Esophagitis plus } \\
\text { other diagnosis (\%) }\end{array}$ & Total (\%) \\
\hline Total & $1520(66.9)$ & $221(9.7)$ & 279 (12.3) & $253(11.1)$ & $2273(100.0)$ \\
\hline \multicolumn{6}{|l|}{ Sex } \\
\hline Female & 901 (59.3) & $136(61.5)$ & $168(60.2)$ & $141(55.7)$ & $1346(59.2)$ \\
\hline Male & $573(37.7)$ & $71(32.1)$ & $102(36.6)$ & 101 (39.9) & 847 (37.3) \\
\hline $\mathrm{N} / \mathrm{A}$ & $46(3.0)$ & $14(6.4)$ & $9(3.2)$ & $11(4.3)$ & $80(3.5)$ \\
\hline \multicolumn{6}{|l|}{ Age (years) } \\
\hline$<15$ & $6(0.4)$ & $0(0.0)$ & $1(0.4)$ & $0(0.0)$ & $7(0.3)$ \\
\hline $16-20$ & $11(0.7)$ & $9(4.1)$ & $8(2.9)$ & $4(1.6)$ & $32(1.4)$ \\
\hline $21-30$ & $96(6.3)$ & $20(9.0)$ & $31(11.1)$ & $15(5.9)$ & $162(7.1)$ \\
\hline $31-40$ & 255 (16.8) & $49(22.2)$ & $51(18.3)$ & $42(16.6)$ & 397 (17.5) \\
\hline $41-55$ & $549(36.1)$ & $82(37.1)$ & $90(32.2)$ & 77 (3.0) & 798 (35.1) \\
\hline$>56$ & $584(38.4)$ & $58(26.2)$ & 89 (31.9) & $114(45.1)$ & 845 (37.2) \\
\hline $\mathrm{N} / \mathrm{A}$ & $19(1.3)$ & $3(1.4)$ & $9(3.2)$ & $1(0.4)$ & $32(1.4)$ \\
\hline \multicolumn{6}{|l|}{ Race } \\
\hline White & $1122(73.8)$ & $156(70.6)$ & $212(76.0)$ & $184(72.7)$ & $1674(73.6)$ \\
\hline Asian & $56(3.7)$ & $14(6.3)$ & $13(4.7)$ & $15(5.9)$ & $98(4.3)$ \\
\hline Black & $18(1.2)$ & $5(2.3)$ & $3(1.1)$ & $3(1.2)$ & $29(1.3)$ \\
\hline Other & $46(3.0)$ & $10(4.5)$ & $10(3.6)$ & $14(5.5)$ & $80(3.5)$ \\
\hline $\mathrm{N} / \mathrm{A}$ & 278 (18.3) & $36(16.3)$ & $41(14.7)$ & $37(14.6)$ & $392(17.2)$ \\
\hline Weight $(\mathrm{kg})$, mean $\pm \mathrm{SD}$ & $76.9 \pm 16.7$ & $70.4 \pm 16.2$ & $72.6 \pm 17.1$ & $73.8 \pm 16.5$ & $75.3 \pm 16.8$ \\
\hline $\mathrm{n}$ & 1350 & 206 & 250 & 228 & 2034 \\
\hline
\end{tabular}

N/A Data not available 
TABLE 5

Prevalence of alarm symptoms or features of serious disease in 2273 patients with respect to the physicians' diagnosis at enrolment in a study of the relief of upper gastrointestinal dyspeptic symptoms with the use of a proton pump inhibitor

\begin{tabular}{|c|c|c|c|c|}
\hline & $\begin{array}{l}\text { Reflux esophagitis } \\
\text { alone (\%) }\end{array}$ & $\begin{array}{l}\text { Peptic ulcer plus } \\
\text { other diagnosis (\%) }\end{array}$ & $\begin{array}{c}\text { Other } \\
\text { diagnosis (\%) }\end{array}$ & $\begin{array}{l}\text { Esophagitis } \\
\text { plus other (\%) }\end{array}$ \\
\hline \multicolumn{5}{|c|}{ Concomitant illness $(n=2269)$} \\
\hline Yes & $717(47.3)$ & $81(36.7)$ & $129(46.2)$ & $116(45.8)$ \\
\hline No & $799(52.7)$ & $140(63.3)$ & $150(53.8)$ & $137(54.2)$ \\
\hline \multicolumn{5}{|c|}{ Dysphagia $(n=2269)$} \\
\hline Yes & $320(21.4)$ & $25(11.4)$ & $48(17.2)$ & $56(22.2)$ \\
\hline No & $1198(78.6)$ & $195(88.6)$ & $231(82.8)$ & $196(77.8)$ \\
\hline \multicolumn{5}{|c|}{ Odynophagia ( $\mathrm{n=2269)}$} \\
\hline Yes & $202(13.3)$ & $10(4.4)$ & $20(7.2)$ & $46(18.3)$ \\
\hline No & $1316(86.7)$ & $210(95.6)$ & $259(92.8)$ & $206(81.7)$ \\
\hline \multicolumn{5}{|c|}{ Vomiting $(\mathrm{n}=2271)$} \\
\hline Yes & $115(7.6)$ & $38(17.2)$ & $30(10.8)$ & $30(11.9)$ \\
\hline No & $1404(92.4)$ & $183(82.8)$ & $249(89.2)$ & $222(88.1)$ \\
\hline \multicolumn{5}{|c|}{ Asthma $(n=2271)$} \\
\hline Yes & $99(6.5)$ & $13(5.9)$ & $15(5.4)$ & $15(6.0)$ \\
\hline No & $1420(93.5)$ & $208(94.1)$ & $264(94.6)$ & $237(94.0)$ \\
\hline \multicolumn{5}{|c|}{ Weight loss $(n=2270)$} \\
\hline Yes & $64(4.2)$ & $25(11.3)$ & $22(7.9)$ & $22(8.7)$ \\
\hline No & $1454(95.8)$ & $196(88.7)$ & $257(92.1)$ & $230(91.3)$ \\
\hline \multicolumn{5}{|c|}{ Melena $(n=2270)$} \\
\hline Yes & $9(0.6)$ & $12(5.5)$ & $9(3.2)$ & $6(2.4)$ \\
\hline No & $1510(99.4)$ & $208(94.5)$ & $270(96.8)$ & $246(97.6)$ \\
\hline \multicolumn{5}{|c|}{ Hematemesis $(n=2270)$} \\
\hline Yes & $5(0.3)$ & $8(3.6)$ & $1(0.4)$ & $2(0.8)$ \\
\hline No & $1514(99.7)$ & $212(96.4)$ & $278(99.6)$ & $250(99.2)$ \\
\hline
\end{tabular}

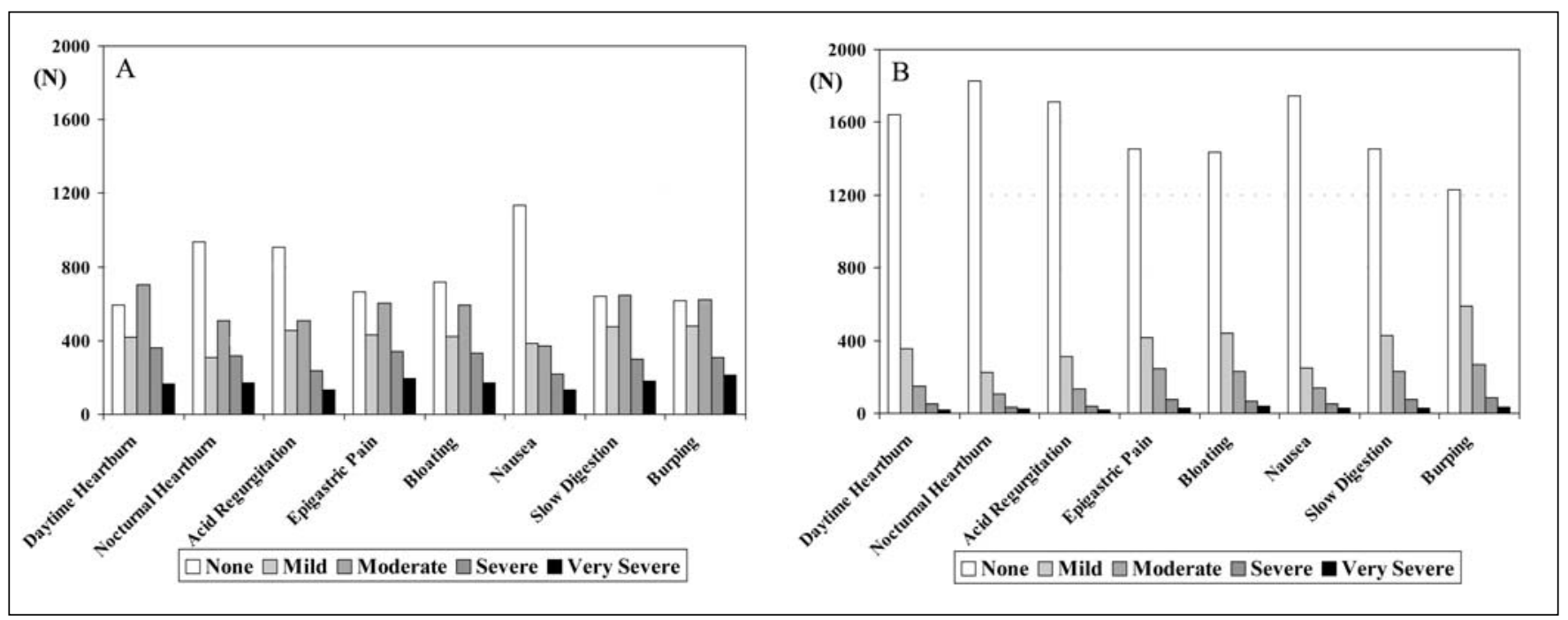

Figure 1) Upper gastrointestinal dyspeptic symptoms recorded in the daily symptom diary at baseline (day $0, A)$ and after seven daily doses of pantoprazole $40 \mathrm{mg}$ (day 7, B). The columns show the absolute numbers of patients with and without each symptom and the number of patients with each symptom who had mild, moderate, severe or very severe symptoms 


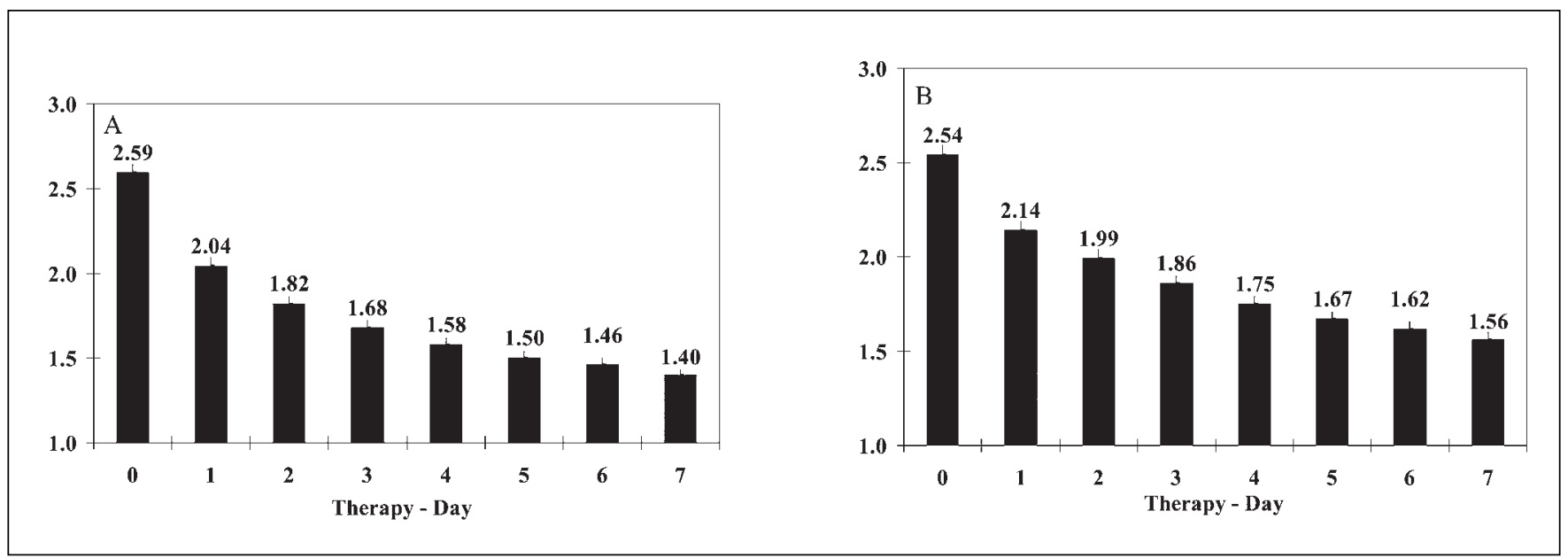

Figure 2) Daily symptom severity scores at baseline (day 0) and during the first seven days of treatment with pantoprazole $40 \mathrm{mg}$ daily, showing the group mean score (mean \pm 2 SE) for daytime heartburn (A) and epigastric pain (B). Symptom severity: $1=$ none, $2=$ mild, $3=$ moderate, $4=$ severe, 5 = very severe

\section{RESULTS}

Recruitment

Patients were recruited over a 20-month period from May 1998 until December 1999. Overall, 726 physicians participated and enrolled at least one patient; there were $601 \mathrm{fam}-$ ily physicians, 39 surgeons, 22 internists and 64 gastroenterologists (Table 1). In total, 3261 patients received the questionnaire and a one-month supply of pantoprazole $40 \mathrm{mg}$ tablets. Of the 3261 patients enrolled, 988 $(30.3 \%)$ patients' data were incomplete (Table 2), while 2273 patients' data were evaluable for at least one symptom before and after treatment. Data on the severity of all symptoms, before and after therapy, were available for 2216 patients. Patients excluded from the analysis differed from those with evaluable data in that the latter had a greater prevalence of concomitant illness and a lower prevalence of vomiting, melena and hematemesis (Table 3). The initial questionnaire was completed within 15 days of entry into the study by $2138(94.1 \%)$ patients with evaluable data and within 31 days of entry by $2201(96.8 \%)$ patients. The median time between completion of the first part of the questionnaire and completion of the second part of the questionnaire was 29 days.

At enrolment, the physician recorded the following diagnoses, alone or in combination, for the patients with evaluable data: 1773 patients (78\%) with reflux esophagitis, 207 (9.1\%) with duodenal ulcer, 103 (4.5\%) with gastric ulcer and 476 (20.9\%) with another diagnosis. For the purposes of further analysis, patients were divided into four groups, according to whether they had a single diagnosis of reflux esophagitis alone, peptic ulcer disease (gastric and/or duodenal ulcer with or without another diagnosis apart from esophagitis), other upper gastrointestinal disease, or reflux esophagitis with another disease (peptic ulcer or other disease). Patients with reflux esophagitis were older and heavier $(\mathrm{P}<0.0001)$ than those with peptic ulcer or other diagnoses (Table 4). In addition, patients with reflux
TABLE 6

Symptom severity score at baseline and after seven days of pantoprazole therapy, determined from patients' daily diaries

\begin{tabular}{lcc}
\hline & \multicolumn{2}{c}{$\begin{array}{c}\text { Symptom severity score } \\
\text { (mean } \pm 2 \text { SE) }\end{array}$} \\
& Baseline (day 0) & Day 7 \\
\hline Daytime heartburn & $2.59(0.052)$ & $1.40(0.033)$ \\
Nocturnal heartburn & $2.32(0.056)$ & $1.29(0.030)$ \\
Acid regurgitation & $2.21(0.052)$ & $1.35(0.031)$ \\
Epigastric pain & $2.54(0.054)$ & $1.56(0.038)$ \\
Bloating & $2.47(0.054)$ & $1.57(0.039)$ \\
Nausea & $2.03(0.052)$ & $1.36(0.034)$ \\
Slow digestion & $2.51(0.053)$ & $1.56(0.039)$ \\
Burping & $2.56(0.054)$ & $1.69(0.040)$ \\
\hline
\end{tabular}

$P<0.00001$ day 7 versus day 0 for all symptoms (paired $t$ test, $n=2273$ ). Symptom severity: $1=$ none, $2=$ mild, $3=$ moderate, $4=$ severe, $5=$ very severe

esophagitis were more likely than those with peptic ulcer to have concomitant illness $(\mathrm{P}=0.0036)$, dysphagia $(\mathrm{P}=0.00073)$ or odynophagia $(\mathrm{P}=0.0032)$, and less likely to have weight loss $(\mathrm{P}=0.00002)$, vomiting $(\mathrm{P}<0.00001)$, melena $(\mathrm{P}<0.00001)$ or hematemesis $(\mathrm{P}<0.00001)$; asthma $(\mathrm{P}=0.83)$ was equally common in all diagnostic groups (Table 5).

\section{Symptom response}

The number of patients who recorded symptoms of any severity in the daily diary before the start of treatment (day $0[$ Figure 1A]) fell significantly by day 7 for all symptoms (Figure 1B). In addition, the severity score for each symptom fell progressively over the seven-day study period (Figure 2), and the reduction in severity score from baseline 
TABLE 7

Proportions of patients with each symptom who became symptom-free during the first seven days of pantoprazole therapy $(n=2273)^{*}$

\begin{tabular}{|c|c|c|c|c|}
\hline & Total & $\begin{array}{l}\text { ptoms } \\
\text { lay } 0 \\
\text { No } \\
\text { symptoms } \\
\text { at day } 7(\%)\end{array}$ & $\begin{array}{r}\text { No sy } \\
\text { at }\end{array}$ & $\begin{array}{l}\text { mptoms } \\
\text { day } 0 \\
\text { Symptoms at } \\
\text { day } 7(\%)\end{array}$ \\
\hline $\begin{array}{l}\text { Daytime } \\
\text { heartburn }\end{array}$ & 1623 & $1106(68.1)$ & 583 & $56(9.6)$ \\
\hline $\begin{array}{l}\text { Nocturnal } \\
\text { heartburn }\end{array}$ & 1284 & $943(73.4)$ & 924 & $47(5.1)$ \\
\hline $\begin{array}{l}\text { Acid } \\
\text { regurgitation }\end{array}$ & 1313 & $875(66.6)$ & 890 & $63(7.1)$ \\
\hline $\begin{array}{l}\text { Epigastric } \\
\text { pain }\end{array}$ & 1548 & 857 (55.4) & 657 & $66(10.0)$ \\
\hline Bloating & 1494 & $784(52.5)$ & 709 & $64(9.0)$ \\
\hline Nausea & 1089 & 706 (64.8) & 1116 & $84(7.5)$ \\
\hline Slow digestion & 1579 & 871 (55.2) & 628 & $56(8.9)$ \\
\hline Burping & 1594 & $702(44.0)$ & 607 & $85(14.0)$ \\
\hline
\end{tabular}

${ }^{*}$ Many patients had multiple symptoms. $P<0.00001$ day 7 versus day 0 for all symptoms (paired t test, $n=2273$ ). Symptom severity: $1=$ none, $2=$ mild, $3=$ moderate, $4=$ severe, $5=$ very severe

to day 7 was statistically significant for all symptoms (Table 6). Symptom relief at day 7 was documented in $44.0 \%$ (burping) to $73.4 \%$ (nocturnal heartburn) of patients who had symptoms at day 0 ; conversely, symptoms developed in $5.1 \%$ (nocturnal heartburn) to $14.0 \%$ (burping) of patients who had not had these symptoms at day 0 (Table 7). Overall, $4.0 \%$ of patients were completely symptom-free at day 0 , whereas by day $7,32.5 \%$ were free of all symptoms and the proportion of patients with severe or very severe symptoms had fallen from $53.5 \%$ to $13.8 \%$ (Table 8 ).

\section{TABLE 8}

Numbers of patients at day 0 and at day 7 who were completely symptom-free ('None'), had at least one symptom of mild or moderate severity but no severe or very severe symptoms ('Mild/moderate') or at least one symptom that was severe or very severe ('Severe/very severe')

\begin{tabular}{lcccc}
\hline Symptoms & \multicolumn{5}{c}{$\begin{array}{c}\text { Symptoms at day 7 } \\
\text { Mild/ } \\
\text { at day 0 }\end{array}$} & None & $\begin{array}{c}\text { Severe/ } \\
\text { moderate }\end{array}$ & $\begin{array}{c}\text { very severe } \\
\text { Total (\%) }\end{array}$ \\
\hline None & 68 & 17 & 5 & $90(4.0)$ \\
$\begin{array}{l}\text { Mild/moderate } \\
\text { Severe/very }\end{array}$ & 353 & 554 & 34 & $941(42.5)$ \\
$\quad 299$ & 620 & 266 & $1185(53.5)$ \\
$\quad \begin{array}{l}\text { severe } \\
\text { Total (\%) }\end{array}$ & $720(32.5)$ & $1191(53.7)$ & $305(13.8)$ & $2216(100)$ \\
\hline
\end{tabular}

$P<0.00001$ day 7 versus day 0 for all symptoms (paired t test, $n=2273$ ). Symptom severity: $1=$ none, $2=$ mild, $3=$ moderate, $4=$ severe, $5=$ very severe

The decline in symptom severity for daytime heartburn and epigastric pain during the first seven days of therapy was also related to the frequency of symptoms recorded at the time of the initial questionnaire. Patients with more frequent heartburn symptoms recorded a greater reduction in daytime heartburn severity (Figure 3A), and those with more frequent upper abdominal symptoms recorded a greater reduction in epigastric pain severity (Figure 3B). Symptom frequency was correlated with symptom severity and, in general, patients with more severe symptoms at baseline also reported a greater improvement in symptoms after seven days (results not shown).

Symptom subgroups

Based on the symptoms recorded in the daily diary $(4,7,8)$, patients were identified as having 'reflux-like' symptoms, 'ulcer-like' symptoms or 'dysmotility-like' symptoms. Overall, the mean total symptom severity score for all eight

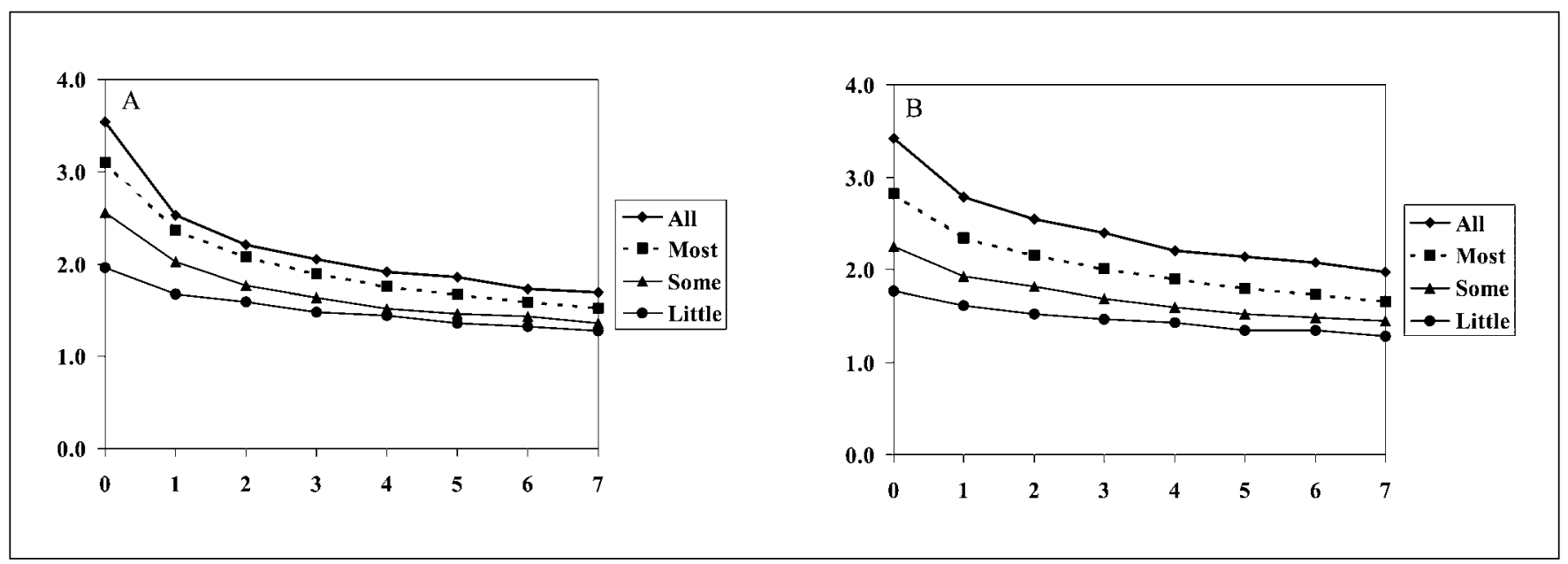

Figure 3) Daily symptom severity scores at baseline (day 0) and during the first seven days of treatment with pantoprazole $40 \mathrm{mg}$ daily, showing the group mean score for daytime heartburn (A) and epigastric pain (B) with respect to the frequency of the symptoms at Day 0 . Symptom severity: $1=$ none, $2=$ mild, $3=$ moderate, $4=$ severe, $5=$ very severe. Symptom frequency: All = almost continuous, Most $=$ most of the time, Some $=$ intermittent, Little $=$ very occasional 
symptoms in all 2273 patients fell significantly from day 0 (baseline) to day $7(2.41 \pm 0.02$ [SE] to $1.47 \pm 0.02 ; \mathrm{P}<0.001$, paired $t$ test). The symptom subgroup severity scores for all patients fell similarly when the symptom subgroups were scored separately, although the reduction in severity score was smallest for the 'dysmotility-like' cluster of symptoms (Figure 4). The reduction in symptom scores was further examined with respect to the physicians' diagnostic groups:

- The decrease in severity scores for 'reflux-like' symptoms was most marked in patients identified by their physicians with a diagnosis of reflux esophagitis, alone (Figure 5A) or in combination (Figure 5D).

- The decrease in severity scores for 'ulcer-like' symptoms was more marked in patients who had been given a diagnosis of peptic ulcer (Figure 5B), other upper gastrointestinal disorder (Figure 5C) or reflux esophagitis with other upper gastrointestinal disease (Figure 5D), compared with patients who had reflux esophagitis alone. In general, 'dysmotility-like' symptoms responded less well, regardless of the physician's initial diagnosis.

\section{DISCUSSION}

The survey described in the present article evaluated upper gastrointestinal dyspeptic symptoms in Canadian clinical practice and documented their response to short term therapy with a PPI. PPIs such as pantoprazole are effective in the management of reflux esophagitis, endoscopy-negative reflux disease, ulcer disease, nonsteroidal anti-inflammatory drug (NSAID)-related ulcer disease and functional dyspepsia. Thus, empirical PPI therapy is a plausible short term, initial strategy for many common upper gastrointestinal tract symptoms (3) and a reasonable long term strategy for those with an established diagnosis of acid-peptic disease. The results of this survey suggest that GERD, including reflux esophagitis, is the major acid-related upper gastrointestinal condition; $78 \%$ of patients were identified as having reflux esophagitis, with or without another upper gastrointestinal condition. However, the investigators were not asked to report on a history of NSAID ingestion, Helicobacter pylori infection or prior $H$ pylori eradication therapy $(11,12)$.

Although the symptom of heartburn is relatively specific for the diagnosis of reflux disease, dyspeptic symptoms were generally nonspecific in this survey, as in previous studies. For example, Talley et al (13) reported peptic ulcers in 11\% of patients with reflux-like dyspeptic symptoms, in $9 \%$ of those with ulcer-like symptoms and in $7 \%$ of those with dysmotility-like symptoms, while Carlsson et al (14) reported that up to $20 \%$ of gastric ulcers may present with reflux-like symptoms. Several other studies have also produced data to indicate that there is considerable overlap between symptom subgroups (13), which, therefore, have little clinical use (15-18).

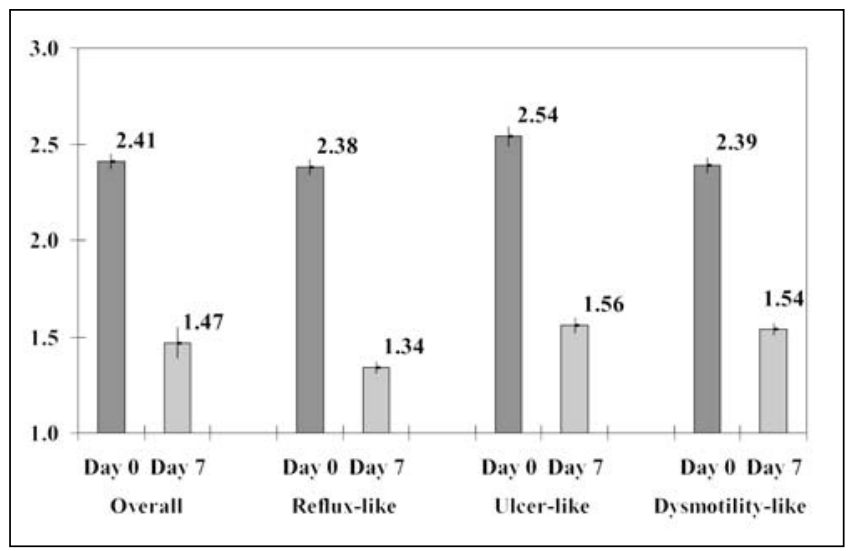

Figure 4) Overall mean symptom scores (mean \pm 2 SE) at baseline (day 0: dark grey columns) and after seven daily doses of pantoprazole $40 \mathrm{mg}$ (day 7: light grey columns) for all patients and also for those in the subgroups of 'reflux-like', 'ulcer-like' and 'dysmotility-like' symptoms

Data from the daily diary card indicate that prompt and effective relief of upper gastrointestinal tract dyspeptic symptoms occurred within seven days of starting PPI therapy and that the improvement in symptoms was most marked for heartburn and epigastric pain, typical of gastroesophageal reflux disease and peptic ulcer, respectively. Many other upper gastrointestinal symptoms also improved, albeit to a lesser extent, over the one-week treatment period. This was not a controlled trial; therefore, it is not possible to distinguish improvements in symptoms attributable to PPI therapy from those related to the adoption of lifestyle measures or to a placebo effect (4).

Large observational surveys have strengths and weaknesses that differ from those of standard randomized, controlled trials; the present survey did not compare different treatment strategies, and there were no investigations to confirm the physicians' initial diagnosis. In some cases, the prescribing physician was a surgeon or gastroenterologist who would have had access to endoscopy or other diagnostic tests and, in many of the other cases, there may have been prior investigations that were not noted in the questionnaire. The major advantage of this survey is that it constitutes a large sample of patients and physicians - family physicians and specialists - from across Canada. However, most patients came from a primary care practice setting; therefore, the results should be broadly representative of primary care patients in Canada.

Overall, 3261 patients were identified, and full evaluable data were available for 2273 (69.7\%). Patients excluded from the analysis were essentially similar to those for whom complete data were available. Furthermore, the fact that vomiting, hematemesis and melena were common in those who did not complete the survey suggests that the presence of alarm symptoms may have led to a change in management strategy and that the pantoprazole may have been a temporizing manoeuvre in these patients while other more definitive arrangements were being made. Alarm features 


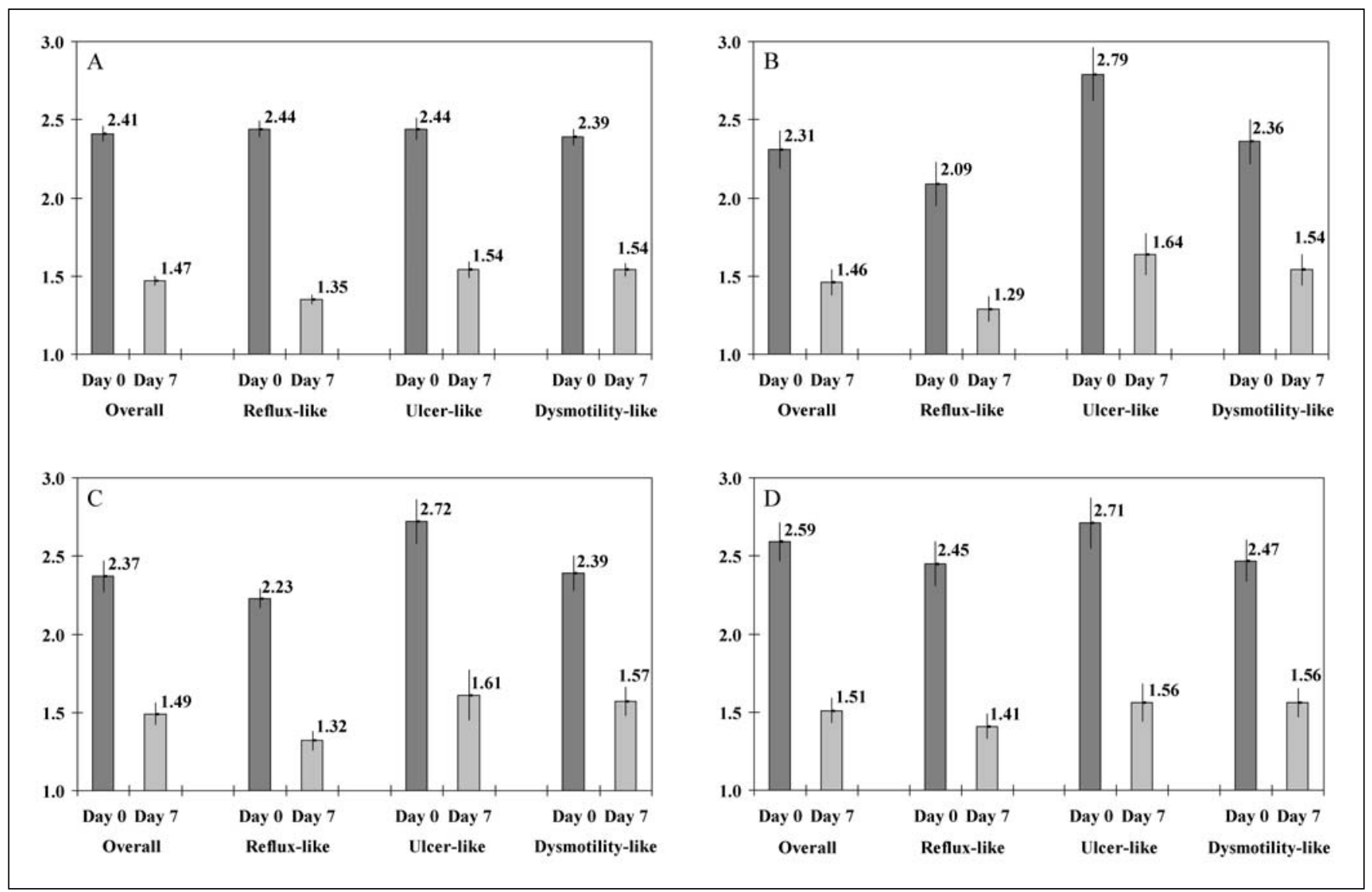

Figure 5) Symptom scores (mean \pm 2 SE) at baseline (day 0: dark grey columns) and after seven daily doses of pantoprazole $40 \mathrm{mg}$ (day $7:$ light grey columns) for all patients and also for those in the subgroups of 'reflux-like', 'ulcer-like' and 'dysmotility-like' symptoms with respect to the physician's initial diagnosis of reflux esophagitis (A), peptic ulcer (B), other upper gastrointestinal disease (C) or reflux esophagitis with other upper gastrointestinal disease $(D)$

such as weight loss, dysphagia, odynophagia and vomiting were common $-29.6 \%$ in patients with evaluable data and there was also an appreciable number of patients with hematemesis and melena. Dysphagia and odynophagia are more prevalent than is generally supposed, and other studies have reported dysphagia in up to $25 \%$ of patients with reflux disease in the absence of malignancy or other significant lesion $(19,20)$. Hematemesis, recorded in 32 of 3261 patients $(1 \%)$, was rare, and the fact that these patients were given a course of oral pantoprazole does not necessarily indicate that potential alarm features were ignored. It is possible that the patients were referred appropriately for prompt consultation and investigation. Prompt investigation is not generally feasible in primary care practice and, under these circumstances, effective initial therapy is very important. Nonetheless, it is important to emphasize the need for prompt investigation for any dyspeptic patient who has one or more of the generally accepted alarm features for upper gastrointestinal disease (3).

Ideally, treatment should be based on a firm diagnosis, but dyspeptic symptoms are common, affecting up to $30 \%$ of the population (1) and accounting for 7\% of primary care practice visits (2). Waiting lists for consultation and endoscopy in parts of Canada are long, ranging from three to six months (2); therefore, family physicians must have access to effective, empirical therapy to provide symptomatic relief for patients who are awaiting further investigation. It is for this reason that guidelines have been developed to guide family physicians regarding the role of empirical therapy for upper gastrointestinal disease (3). Some guidelines are based on the notion that reflux disease can be diagnosed on the basis of symptoms alone (10); others emphasize the importance of identifying patients with alarm features that should lead to prompt investigation, without necessarily precluding symptomatic therapy. The results of this survey suggest that, for the most part, PPIs are prescribed for appropriate indications. A high proportion of the patients treated had symptoms indicative of upper gastrointestinal, acid-related disease, and their dyspeptic symptoms, particularly those suggestive of reflux disease, responded promptly in most cases.

There was significant improvement in all symptom types over seven days of therapy. Symptom severity declined rapidly over the first one to two days, and by the end of the seven-day treatment period, the mean severity score was equivalent to 'absent' or 'mild' symptoms. The change in 
severity scores was highly significant for all symptoms. The proportion of patients who became symptom-free during the first seven days ranged from $44 \%$ for burping to $73.4 \%$ for nocturnal reflux symptoms. Although this was not a placebo controlled survey, the proportion of patients who became completely symptom-free is comparable with that reported for patients with endoscopy-negative reflux disease (21-25) or uninvestigated dyspepsia in primary care practice (25-28). Furthermore, it is likely that much of the decrease in symptoms was due to acid suppression, because typical, acid-related symptoms such as nocturnal heartburn responded to treatment in a greater proportion of patients and appeared or recurred in the smallest proportion of patients, while the converse was true for acid-unrelated symptoms such as burping. Finally, the greatest improvements in symptom severity were noted in patients whose symptoms were most frequent, suggesting that the symptomatic response to therapy was related to acid suppression rather than to a nonspecific, placebo effect.

The physicians' presumptive diagnosis, recorded before the patient's enrolment, was not associated with any major differences in the symptomatic response to treatment after seven days, although there was a trend to a greater decrease in 'reflux-like' symptoms for patients with a diagnosis of reflux esophagitis as well as a greater decrease in 'ulcer-like' symptoms for those with a diagnosis of peptic ulcer. Similarly, clustering of symptoms according to symptom subgroups was not associated with a significant difference in symptom response, although patients with 'dysmotility-like' symptoms tended to have a smaller decrease in symptom severity, whereas those with 'reflux-like' symptoms responded to a somewhat greater extent. 'Dysmotility-like' symptoms are generally considered to respond poorly to acid suppression; however, data from a recent randomized, controlled trial indicate that patients with dysmotility-like dyspepsia respond better to PPI therapy than to a prokinetic agent (29), although the response is less in 'dysmotility-like'

\section{REFERENCES}

1. Tougas G, Chen Y, Hwang P, Liu MM, Eggleston A. Prevalence and impact of upper gastrointestinal symptoms in the Canadian population: findings from the DIGEST study. Domestic/International Gastroenterology Surveillance Study. Am J Gastroenterol 1999:94:2845-54.

2. Chiba N, Bernard L, O'Brien BJ, Goeree R, Hunt RH. Canadian physician survey of dyspepsia management. Can J Gastroenterol 1998;12:83-90.

3. Veldhuyzen van Zanten SJO, Flook N, Chiba N, et al. An evidencebased approach to the management of uninvestigated dyspepsia in the era of Helicobacter pylori. CMAJ 2000;162(Suppl 12):S1-23.

4. Talley NJ, Stanghellini V, Heading R, Koch KL, Malagelada JR, Tytgat GNJ. Functional gastroduodenal disorders. Gut 1999;45(Suppl 2):I37-42.

5. Armstrong D, Bennett JR, Blum AL, et al. The endoscopic assessment of esophagitis: a progress report on observer agreement. Gastroenterology 1996;111:85-92.

6. Dent J, Brun J, Fendrick AM, et al. An evidence-based appraisal of reflux disease management: the Genval Workshop Report. Gut 1999;44(Suppl 2):S1-6.

7. Talley NJ, Colin-Jones D, Koch KL, Koch M, Nyrén O, Stanghellini V. Functional dyspepsia: a classification with guidelines for diagnosis and management. Gastroenterol Int 1991;4:145-60. than in 'reflux-like' dyspepsia. PPI therapy probably resulted in an improvement in symptoms of 'dysmotilitylike' dyspepsia because dyspeptic symptom clusters are heterogeneous and, thus, are not good predictors of the origin of symptoms $(13,17)$.

In summary, these data suggest that pantoprazole produces rapid symptomatic relief in patients with upper gastrointestinal tract dyspeptic symptoms. Within seven days of starting therapy, the majority of patients had symptoms that were of moderate severity or less, and over $30 \%$ of patients had become completely symptom free. The presence of reflux-like symptoms is probably the best predictor of symptom response, but the physicians' presumptive diagnosis has little predictive value with respect to the relief of specific symptoms. A high proportion of patients had potential alarm features, and although there are no data on the subsequent management of these patients, it is important to emphasize the importance of identifying alarm features in primary care practice, with a view to arranging prompt investigation (3).

In a predominantly primary care population, such as that in the present survey, PPI therapy is likely to produce a good symptomatic response for patients with upper gastrointestinal symptoms. This empirical, 'step-down' approach, starting with a PPI for optimal acid suppression, rather than with antacids or a histamine $\mathrm{H}_{2}$-receptor antagonist, is reasonable provided that patients are followed up to ensure that continued therapy is appropriate and that further investigation is not necessary. Many patients have potential alarm symptoms, and future studies should be designed to address how such patients should be managed because it is highly unlikely that they all have serious disease.

ACKNOWLEDGEMENTS: This survey was funded by Solvay Pharma Inc and Byk Canada Inc. Results have been presented, in part, in abstract form, in reference 30.

8. Colin-Jones DG, Bloom B, Bodemar G, et al. Management of dyspepsia: report of a working party. Lancet 1988;i:576-9.

9. Bytzer P, Hansen JM, Havelund T, Malchow-Moller A, Schaffalitzky de Muckadell OB. Predicting endoscopic diagnosis in the dyspeptic patient: the value of clinical judgement. Eur J Gastroenterol Hepatol 1996;8:359-63.

10. Carlsson R, Dent J, Bolling-Sternevald E, et al. The usefulness of a structured questionnaire in the assessment of symptomatic gastroesophageal reflux disease. Scand J Gastroenterol 1998;33:1023-9.

11. Hunt RH, Thomson ABR, Consensus Conference participants. Canadian Helicobacter pylori Consensus Conference. Can J Gastroenterol 1998;12:31-41.

12. Hunt RH, Fallone CA, Thomson ABR, Canadian Helicobacter Study Group. Canadian Helicobacter pylori consensus conference update: infection in adults. Can J Gastroenterol 1999;13:213-7.

13. Talley NJ, Weaver AL, Tesmer DL, Zinsmeister AR. Lack of discriminant value of dyspepsia subgroups in patients referred for upper endoscopy. Gastroenterology 1993;105:1378-86.

14. Carlsson R, Frison L, Lundell L, et al. Relationship between symptoms, endoscopic findings and treatment outcome in reflux esophagitis. Gastroenterology 1996;110:A77. (Abst)

15. Inoue M, Sekiguchi T, Harasawa S, Miwa T, Miyoshi A. Dyspepsia 
and dyspepsia subgroups in Japan: symptom profiles and experience with cisapride. Scand J Gastroenterol Suppl 1993;195:36-9.

16. Heading RC and the Dyspepsia Study Group. Upper gastrointestinal symptoms in general practice: a multicentre UK study. J Drug Dev Clin Pract 1995;7:109-17.

17. Johnsen R, Bernerson B, Straume B, Forde OH, Bostad L, Burhol PG. Prevalences of endoscopic and histological findings in subjects with and without dyspepsia. BMJ 1991;302:749-52.

18. Klauser AG, Voderholzer WA, Knesewitsch PA, Schindlbeck NE, Müller-Lissner SA. What is behind dyspepsia? Dig Dis Sci 1993;38:147-54.

19. Dakkak M, Hoare RC, Maslin SC, Bennett JR. Oesophagitis is as important as oesophageal stricture diameter in determining dysphagia. Gut 1993;34:152-5.

20. Kahrilas PJ, Falk GW, Johnson DA, et al. Esomeprazole improves healing and symptom resolution as compared with omeprazole in reflux oesophagitis patients: a randomized, controlled trial. Aliment Pharmacol Ther 2000;14:1249-58.

21. Bate CM, Griffin SM, Keeling PWN, et al. Reflux symptom relief with omeprazole in patients without unequivocal oesophagitis. Aliment Pharmacol Ther 1996;10:547-55.

22. Venables TL, Newland RD, Patel AC, Hole J, Wilcock C, Turbitt ML. Omeprazole 10 milligrams once daily, omeprazole 20 milligrams once daily, or ranitidine 150 milligrams twice daily, evaluated as initial therapy for the relief of symptoms of gastro-oesophageal reflux disease in general practice. Scand J Gastroenterol 1997;32:965-73.

23. Lind T, Havelund T, Carlsson R, et al. Heartburn without oesophagitis: efficacy of omeprazole therapy and features determining therapeutic response. Scand J Gastroenterol 1997;32:974-9.

24. Carlsson R, Dent J, Watts R, et al. Gastro-oesophageal reflux disease in primary care: an international study of different treatment strategies with omeprazole. International GORD Study Group. Eur J Gastroenterol Hepatol 1998;10:119-24.

25. Galmiche JP, Barthelemy P, Hamelin B. Treating the symptoms of gastro-oesophageal reflux disease: a double-blind comparison of omeprazole and cisapride. Aliment Pharmacol Ther 1997;11:765-73.

26. Goves J, Oldring JK, Kerri D, et al. First line treatment with omeprazole provides an effective and superior alternative strategy in the management of dyspepsia compared to antacid/alginate liquid: a multicentre study in general practice. Aliment Pharmacol Ther 1998;12:147-57.

27. Mason I, Millar LJ, Sheikh R, et al. The management of acid-related dyspepsia in general practice: a comparison of an omeprazole versus antacid-alginate/ranitidine management strategy. Aliment Pharmacol Ther 1998;12:263-71.

28. Meineche-Schmidt V, Krag E. Antisecretory therapy in 1017 patients with ulcer-like or reflux-like dyspepsia in general practice. Eur J Gen Pract 1997;3:125-30.

29. Veldhuyzen van Zanten SJO, Chiba N, Armstrong D, et al. A doubleblind, randomised controlled trial comparing omeprazole, ranitidine, cisapride and placebo in 512 Helicobacter pylori $(\mathrm{Hp})$ negative primary care patients with uninvestigated dyspepsia (UD) - The CADET-HN Study. Am J Gastroenterol 2001;96:9. (Abst)

30. Armstrong D, Goeree R, Kazim F, Paré P, Pyzyk M. Upper gastrointestinal symptoms and quality of life: the effect of acid suppression. Can J Gastroenterol 1999;13(Suppl B):151B. (Abst) 


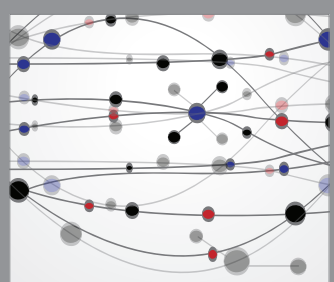

The Scientific World Journal
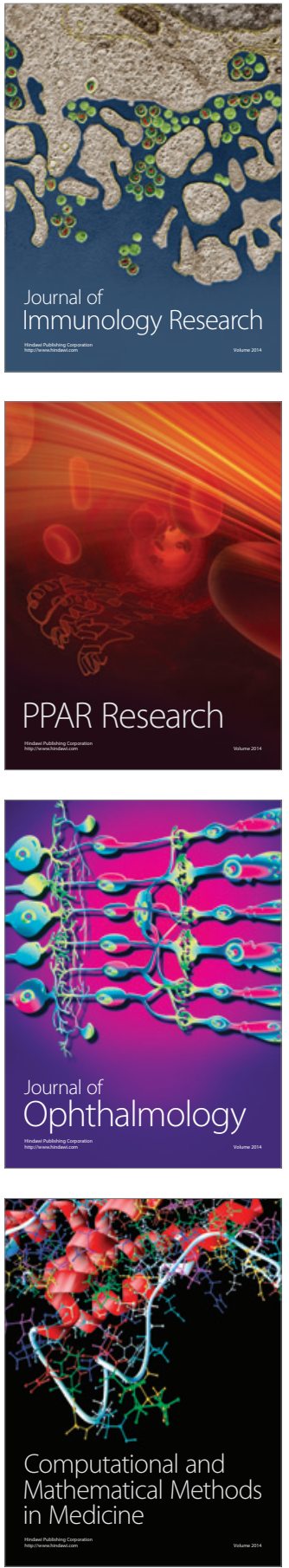

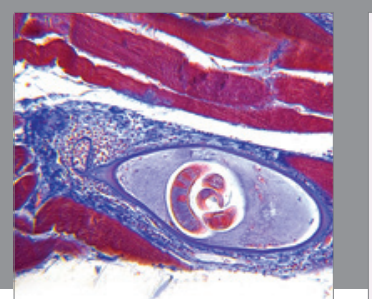

Gastroenterology Research and Practice

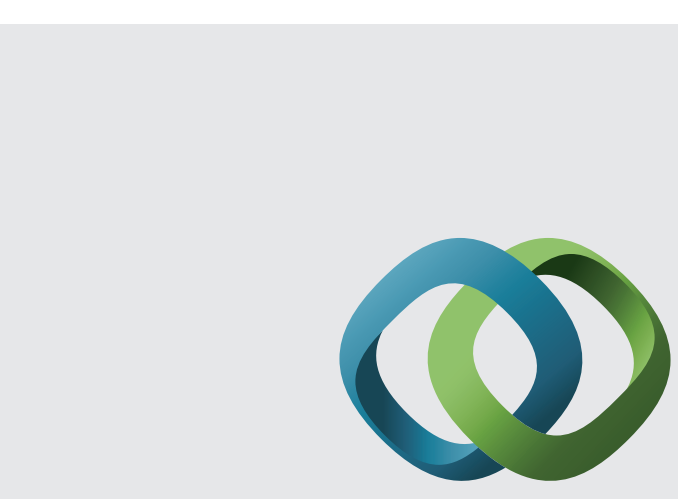

\section{Hindawi}

Submit your manuscripts at

http://www.hindawi.com
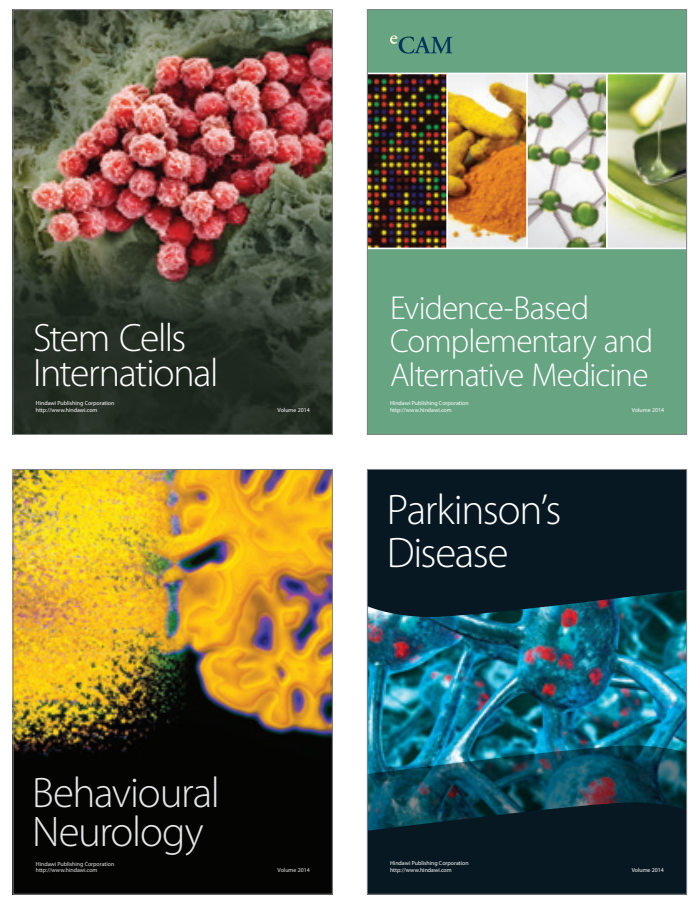
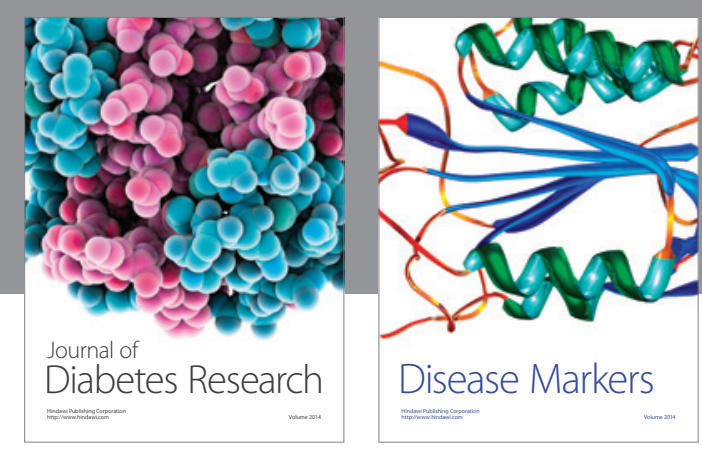

Disease Markers
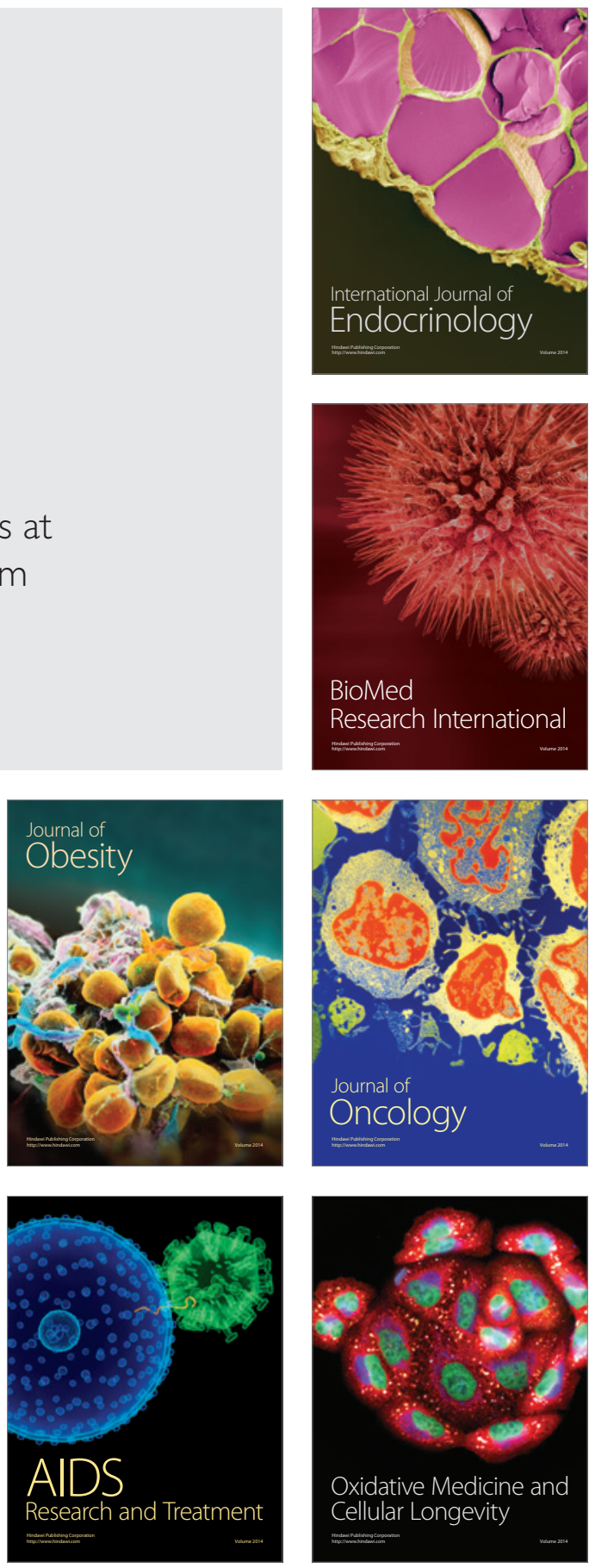